\title{
PENGARUH PEMBIAYAAN MIKRO SYARIAH TERHADAP TINGKAT PERKEMBANGAN USAHA MIKRO KECIL MENENGAH (UMKM) PADA ANGGOTA BMT DI JAWA BARAT
}

\author{
Uus Ahmad Husaeni' ${ }^{1)}$, Tini Kusmayati Dewi ${ }^{2)}$ \\ uusahmadhusaeni@unsur.ac.id \\ 1) 2) Dosen Fakultas Ekonomi dan Bisnis Islam, Universitas Suryakancana \\ (Diterima: 2 Februari 2019; direvisi:10 Maret 2019; dipublikasikan: 09 April 2019 ) \\ (C)2019 -Bongaya Journal for Research in Management STIEM Bongaya. Ini adalah artikel dengan \\ terbuka dibawah licenci CC BY-NC-4.0 (https://creativecommons.org/licenses/by-nc/4.0/ ).
}

\begin{abstract}
This study aims to analyze the role of Islamic microfinance on the level of development of small and medium micro enterprises in BMT members in West Java. The research method is carried out using a type of quantitative associative approach. The population of this study are members of BMT Baytul Ikhtiar Bogor, BMT ItQan Bandung, BMT Amanah Bersama Bandung and BMT Ibadurrahman Sukabumi, which number 40 people. While the technique for analyzing data is using Simple Linear Regression analysis. The results of the study found that the role of Islamic microfinance in providing business capital to members of $B M T$ has an important role to improve small and medium micro enterprises. The R-Square value is 0.529 or $52.90 \%$. It is seen that the independent variable of Islamic microfinance in explaining the dependent variable of SMEs Business Development Levels on BMT members is $52.90 \%$, the remaining $47.10 \%$ is explained by other variables outside the model that are not examined. Based on the results of testing the $F$ test, the value of $F_{\text {count }}>F_{\text {table }}$ is $61.875>3.24$ with the hypothesis $H_{0}$ being rejected and $\mathrm{Ha}$ being accepted with a significance of $0.000<$ 0.05 .
\end{abstract}

Keywords: Islamic microfinance, MSMEs, BMT, and Business.

Abstrak: Penelitian ini bertujuan untuk menganalisis peran pembiayaan mikro syariah terhadap tingkat perkembangan usaha mikro kecil dan menengah pada anggota BMT di Jawa Barat. Metode penelitian dilakukan menggunakan jenis pendekatan asosiatif kuantitatif. Jumlah populasi dari penelitian ini yaitu anggota BMT Baytul Ikhtiar Bogor, BMT ItQan Bandung, BMT Amanah Bersama Bandung dan BMT Ibadurrahman Sukabumi yang berjumlah 40 orang. Sedangkan teknik untuk menganalisa data yaitu menggunakan analisis Regresi Linier Sederhana. Hasil penelitian menemukan bahwa peran pembiayaan mikro syariah dalam memberikan permodalan usaha kepada anggota BMT memiliki peran penting untuk meningkatkan usaha mikro kecil dan menengah. Nilai R-Square sebesar 0.529 atau $52.90 \%$. Hal ini terlihat bahwa variabel independen Pembiayaan Mikro Syariah dalam menjelaskan variabel dependen Tingkat Perkembangan Usaha UMKM pada anggota BMT sebesar 52.90\%, sisanya sebesar $47.10 \%$ dijelaskan oleh variabel lain di luar model yang tidak diteliti. Berdasarkan hasil pengujian uji $\mathrm{F}$, nilai $\mathrm{F}_{\text {hitung }}>\mathrm{F}_{\text {tabel }}$ adalah $61.875>3.24$ dengan hipotesis $\mathrm{H}_{0}$ ditolak dan $\mathrm{H}_{\mathrm{a}}$ diterima dengan signifikansi $0.000<0.05$.

Katakunci: Pembiayaan Mikro Syariah, UMKM, BMT, and Bisnis. 



\section{Uus Ahmad Husaseni, Tini Kusmayati Dewi, Pengaruh Pembiayaan Mikro Syariah Terhadap Tingkat Perkembangan Usaha Mikro Kecil Menengah (UMKM) Pada Anggota BMT dI Jawa Barat}

\section{PENDAHULUAN}

Usaha Mikro Kecil dan Menengah (UMKM) adalah unit usaha produktif yang berdiri sendiri, yang dilakukan oleh orang perorangan atau badan usaha disemua sektor ekonomi (Tambunan, 2012). UMKM merupakan usaha yang mampu bertahan di tengah krisis ekonomi yang telah melanda sejak tahun 1997, bahkan menjadi katup penyelamat bagi pemulihan ekonomi bangsa karena kemampuannya memberikan sumbangan yang cukup signifikan pada PDB maupun penyerapan tenaga kerja (Anggraeni, 2012). Sejak saat itu, peranan UMKM dalam menopang perekonomian nasional maupun regional dari tahun ke tahun baik eksistensi, ketangguhan maupun kontribusinya terus meningkat. Keberhasilan UMKM ini dikarenakan, pertama, UMKM tidak memiliki utang luar negeri dan tidak banyak utang ke perbankan. Kedua, sektor-sektor kegiatan UMKM, seperti pertanian, perdagangan, industri rumah tangga, dan lain-lainnya tidak bergantung sumber bahan baku dari luar negeri. UMKM menggunakan bahan baku lokal yang diperoleh dari potensi daerah sekitar perusahaan. Ketiga, walaupun belum semuanya, UMKM berorientasi ekspor, dapat dikatakan UMKM merupakan soko guru perekonomian nasional. Sumbangan UMKM terhadap produk domestik bruto (PDB) mencapai 54\%-57\%, dan kontribusinya terhadap penyerapan tenaga kerja sekitar 96\% (Darawati, 2013).

\footnotetext{
Berbagai upaya untuk menjadikan UMKM sebagai penggerak roda perekonomian masih menghadapi berbagai tantangan terkait dengan keberadaannya yang bersifat income gathering. Usaha yang dijalankan bertujuan untuk menaikkan pendapatan dengan ciri-ciri umum
}

merupakan usaha milik keluarga, menggunakan teknologi yang masih relatif

sederhana, dan tidak ada pemisahan modal usaha dengan kebutuhan pribadi. Masalah lain yang kemudian muncul seperti keterbatasan modal kerja, kapasitas sumber daya manusia yang rendah, dan minimnya penguasaan ilmu pengetahuan dan teknologi, yang secara umum berimplikasi terhadap prospek usaha yang kurang jelas. Salah satu masalah dalam perkembangan UMKM adalah keterbatasan modal yang dimiliki dan sulitnya mengakses sumber permodalan. Mengutip laporan BPS, Dibyo Prabowo (2004 dalam Kara, 2009) menegaskan bahwa $35.10 \%$ UKM menyatakan kesulitan permodalan, kemudian diikuti oleh kepastian pasar 25.9\% dan kesulitan bahan baku $15.4 \%$. Dalam kondisi yang demikian kelompok ini akan sangat sulit keluar dari permasalahan yang biasanya sudah berjalan lama tersebut, kecuali bila ada intervensi dari pihak lain yaitu lembaga keuangan syariah.

Keterbatasan akses sumber-sumber pembiayaan yang dihadapi oleh pelaku UMKM terutama dari lembaga-lembaga keuangan formal seperti perbankan, menyebabkan mereka bergantung pada sumber-sumber informal. Bentuk dari sumber-sumber ini beraneka ragam mulai dari pelepas uang (rentenir) hingga berkembang dalam bentuk unit-unit simpan pinjam, koperasi dan bentukbentuk lainnya yang lazim disebut sebagai Lembaga Keuangan Mikro (LKM) (Amalia, 2009). Kehadiran lembaga keuangan mikro, dalam hal ini mikro syariah, menjadi peluang cemerlang untuk bisa turut andil dalam pengembangan dan pemberdayaan UMKM. Hal ini dikarenakan dalam perkembangannya, kemudahan akses dan persyaratan yang ditawarkan lembaga 


\section{0 | Bongaya Journal of Research in Management Vol. 2 No. 1 April 2019}

keuangan mikro syariah lebih mengena di kalangan pelaku UMKM karena sifatnya yang lebih fleksibel, misalnya dalam hal persyaratan dan jumlah pinjaman yang tidak seketat persyaratan perbankan maupun keluwesan pada pencairan pembiayaan. Hal ini merupakan salah satu indikator bahwa keberadaan lembaga keuangan mikro syariah sesuai dengan kebutuhan pelaku UMKM, yang umumnya membutuhkan pembiayaan sesuai skala dan sifat usaha kecil (Agyapong, 2010).

Baitul Maal wat Tamwil (BMT) merupakan salah satu lembaga keuangan mikro syariah yang dapat mendukung permodalan UMKM. Hal tersebut mengingat layanan keuangan mikro syariah BMT relative dapat lebih mudah diakses sebagian besar UMKM yang unbankable. Pembiayaan syariah memberikan kelebihan yang tidak dimiliki oleh lembaga konvensional karena tidak adanya sistem bunga yang dapat membebani UMKM (beban bunga yang terus bertambah) (Nizarul, 2009).

Kinerja penyaluran pembiayaan mikro syariah dari BMT semakin meningkat. Berdasarkan data BI pada bulan Oktober 2017 jumlah BMT sebanyak 4.238 unit dengan 3.200.000 Anggota dengan total pinjaman dan total simpanan mencapai 13.09 triliun. Kerjasama BMT dengan Kementrian Koperasi Usaha Kecil dan Menengah pada tahun 2017 melalui program dana bergulir syariah telah menyalurkan pembiayaan pada 326 BMT dengan nilai 400 milyar. Sedangkan kredit macetnya (Non Performing Financing) juga kecil, yaitu $2 \%$.

BMT Baytul Ikhtiar Bogor, BMT ItQan Bandung, BMT Amanah Bersama Bandung dan BMT Ibadurrahman Sukabumi merupakan salah satu BMT dengan total asset terbesar di Jawa Barat. Dan juga merupakan lembaga keuangan mikro syariah yang berbadan hukum koperasi sehingga mampu menyatukan kekuatan-kekuatan ekonomi dan sosial yang kecil-kecil sehingga menjadi kekuatan yang besar, yang pada akhirnya memunculkan semangat untuk mendorong permodalan UMKM pada anggotanya. Oleh karena itu, kontribusi pembiayaan mikro syariah yang disalurkan oleh BMT terhadap tingkat perkembangan usaha UMKM anggota BMT di Jawa Barat sangat menarik untuk diteliti dan layak dikaji lebih lanjut.

\section{TINJAUAN TEORI}

\section{Pembiayaan Mikro Syariah pada UMKM}

Memberikan dan penyaluran dana kembali ke masyarakat merupakan tugas pokok dari bank, yaitu pemberian fasilitas penyediaan dana untuk memenuhi kebutuhan pihakpihak yang merupakan defisit unit (Antonio, 2001). Menurut Pramayati (2008), pemberian pembiayaan Usaha Mikro itu sendiri adalah pinjaman dalam bentuk kredit yang disalurkan oleh pihak perbankan kepada pengusaha UMKM yang dapat dimungkinkan diberikan tetapi belum bankable. Maksudnya adalah usaha tersebut dapat dijadikan sebagai usaha yang berkelanjutan dan dapat memperbaiki taraf hidup di dalam masyarakat.

Menurut Alma (2010) menyatakan bahwa usaha mikro merupakan suatu usaha individu atau keluarga atau yang beranggotakan individu yang belum memiliki izin usaha secara lengkap.Pengertian lain dikemukakan Purnomo (2004), UMKM adalah usaha yang dilakukan oleh suatu perusahaan dengan tenaga kerja yang digunakan tidak melebihi dari 50 orang.Menurut International Management Communications Corporation (IMCC), microfinance sebagai seperangkat teknik dan metode perbankan non-tradisional untuk membuka akses terhadap sektor yang tidak pernah tersentuh oleh jasa keuangan formal (Bustami, 2007).

Pembiayaan mikro adalah fasilitas pembiayaan yang diberikan untuk kelangsungan dari usaha mikro (Ikatan 


\section{Uus Ahmad Husaseni, Tini Kusmayati Dewi, Pengaruh Pembiayaan Mikro Syariah Terhadap Tingkat Perkembangan Usaha Mikro Kecil Menengah (UMKM) Pada Anggota BMT dI Jawa Barat}

Bankir Indonesia, 2014). Adapun usaha mikro menurut Keputusan Menteri Keuangan Nomor 40/KMK.06/2003 tanggal 29 Januari 2003 yaitu: a) Usaha produktif milik keluarga atau perorangan; b) Penjualan maksimal Rp. 100 juta pertahun; c) Kredit yang diajukan maksimal Rp. 50 juta.Menurut Undang-Undang RI Nomor 20 Tahun 2008 tentang usaha mikro, kecil, dan menengah bahwa Usaha Mikro yaitu Usaha produktif milik orang perorangan dan/atau badan usaha perorangan yang memenuhi kriteria usaha mikro sebagaimana diatur dalam Undang-Undang ini. Penggolongan Usaha Mikro yaitu sebagai berikut:1) Memiliki kekayaan bersih paling banyak Rp50.000.000,00 (lima puluh juta rupiah) tidak termasuk tanah dan bangunan tempat usaha; atau (2) Memiliki hasil penjualan tahunan paling banyak Rp300.000.000,00 (tiga ratus juta rupiah).

Badan Pusat Statistik (BPS) menyatakan bahwa yang dikatakan usaha mikro itu terdiri dari 5 orang, termasuk tenaga yang tidak dibayar dan menurut Bank Indonesia, definisi mikro (SK Dir BI No. 31/24/KEP/DIR tgl 5 mei 1998) yang dikelola atau dijalankan masyarakat yang kurang mampu. Dimiliki keluarga yang bersumber dari dalam negeri dan memiliki teknologi yang sangat sederhana. Lapangan usaha mudah untuk exit dan entry (Pramayati, 2008). Pembiayaan salah satu metode menyalurkan dana yang tinggi dari suatu lembaga keuangan bank (Karim, 2010), yang penuh dengan risiko kerugian yang cukup besar (Afkar, 2015). Namun juga memiliki peluang yang besar dalam mendapatkan laba.

Ada beberapa produk pembiayaan mikro syariah yang ditawarkan oleh lembaga keuangan baik bank maupun non bank antara lain: produk simpanan (alwadi'ah); produk bagi hasil (syirkah) yang terdiri dari musyarakah dan mudharabah; produk jual beli $\left(b a^{\prime} i\right)$ yang terdiri dari

murabahah, salam dan istishna serta produk sewa (ijarah).

\section{Tingkat Perkembangan Usaha UMKM}

Menurut Purnomo (2010), adapun usaha yang berkembang itu diklasifikasikan ke dalam 5 tahap, yaitu konseptual, permulaan, stabilitas, pertumbuhan (growth stage), serta kedewasaan. Perkembangan usaha dari segi conceptual,yaitu: a) Mengenal peluang potensial, dalam mengetahui peluang potensial yang terpenting harus diketahui yaitu masalahmasalah yang ada dipasar,kemudian dicari solusi masalah yang telah terdeteksi. Solusi tersebut menjadi ide yang dapat direalisasikan; b) Analisa peluang, tindakan yang bisa dilakukan untuk merespon peluang bisnis adalah dengan melakukan analisa peluang tujuan pasar yang ingin diraih kepada calon pelanggan potensial. Analisa ini dibuat untuk mengetahui respon pelanggan terhadap produk, proses, dan pelayanannya; c) Mengorganisasi sumber daya, yang perlu dilakukan ketika suatu usaha berdiri adalah memanejemen sumber daya manusia dan uang. Tahapan inilah yang sering disebut sebagai permulaan dari suatu usaha. Tahapan inimenjadi sangat berartidikarenakan merupakan kunci keberhasilan untuk tahap selanjutnya. Tahap ini merupakan tahapan awal yang dapat dilakukan atau sering disebut dengan pemanasan (warming up); d) Perpindahan sumber daya, merupakan suatu langkah dimana perpindahan sumber daya dan menerima resiko yaitu suatu langkah dimana langkah terakhir sebelum ke tahap permulaan.

Agar mencapai suatu tujuan yang ingin dicapai usaha dapat berkembang apabila dikelola dan diatur dengan baik, 


\section{2 | Bongaya Journal of Research in Management Vol. 2 No. 1 April 2019}

terproses dan terlihat adanya peningkatan dari waktu ke waktu. Menurut Prawirokusumo (2000) menyatakan bahwa berkembangnya suatu usaha terlihat dengan adanya peningkatan omset penjualan.Pengembangan dapat diartikan sebagai bentuk dalam peningkatan kemampuan konseptual, teoritis, teknis, dan moral individu yang dikembangkan melalui pendidikan dan pelatihan. Pengembangan UKM lebih dituju kepada pelaku ekonomi yang berdaya saing melalui peningkatan wirausaha dan peningkatan produktivitas yang didukung dengan upaya peningkatan adaptasi terhadap kebutuhan pasar, pemanfaatan hasil inovasi dan penerapan teknologi (Afifuddin, 2010). Pengaruh dari pengembangan UMKM di Indonesia dan melihat peran serta pemerintah dalam meningkatkan pertumbuhan UMKM di Indonesia memiliki hasil positif, baik secara langsung maupun tidak langsung (Tambunan, 2009). Pengembangan UMKM pada hakikatnya merupakan tanggungjawab bersama antara pemerintah dan masyarakat. Dengan melihat kendala yang muncul yang sering dihadapi oleh UMKM, maka diperlukan adanya suatu upaya-upaya yaitu: 1) Menciptakan suatu iklim usaha yang kondusif; 2) Bantuan Permodalan; 3) Perlindungan Usaha; 4) Pengembangan Kemitraan; 5) Pelatihan; 6) Mengembangkan Promosi dan 7) Menjalin Kerjasama yang baik (Hafsah, 2004).

\section{Baitul Maal wa Tamwil (BMT)}

Lembaga Keuangan Mikro di Indonesia berdasarkan tipenya secara umum dibagi menjadi tiga yaitu: 1) lembaga formal merupakan sektor keuangan formal yang diatur oleh Undangundang perbankan dan diawasi oleh Bank Indonesia, misalnya Bank Rakyat Indonesia (BRI), Bank Perkreditan Rakyat (BPR); 2) lembaga semi formal merupakan sektor keuangan semi formal yang bukan menjadi subjek dari Undang-undang perbankan tetapi tetap diatur dan diawasi oleh pemerintah selain Bank Indonesia, misalnya Badan Kredit Desa (BKD), Koperasi Unit Desa (KUD), Baitul Maal wat Tamwil (BMT); dan 3) lembaga informal, misalnya rentenir, bank keliling, perjanjian keuangan yang menyangkut lahan, tenaga kerja dan pertukaran barang (Amalia, 2009).

BMT adalah lembaga swadaya masyarakat yang didirikan dan dikembangkan oleh masyarakat terutama pada awal berdiri, biasanya dilakukan dengan menggunakan sumber daya termasuk dana atau modal dari masyarakat setempat itu sendiri. BMT memiliki beberapa kelebihan. Pertama, dalam BMT terkandung dua kepentingan yang saling menunjang yaitu kepentingan sosial dan kepentingan bisnis. Kepentingan sosial direpresentasikan oleh baitul maal dan kepentingan bisnis direpresentasikan oleh baitul tamwil. Kedua, sistem operasi BMT mengacu pada ketentuan-ketentuan Islam, bukan menggunakan sistem bunga seperti pada lembaga keuangan konvensional. Ketiga, pemimpin dan pengurus BMT bertindak aktif, proaktif, dinamis, tidak menunggu tetapi menjemput calon anggota penyimpan atau peminjam (Nizarul, 2009).

\section{METODE PENELITIAN}

Penelitian yang dilakukan menggunakan jenis pendekatan asosiatif kuantitatif. Jumlah populasi dari penelitian ini yaitu anggota BMT Baytul Ikhtiar Bogor, BMT ItQan Bandung, BMT Amanah Bersama Bandung dan BMT Ibadurrahman Sukabumi yang berjumlah 40 orang. Dalam penentuan sampel, peneliti mengambil purposive sampling yakni teknik pengambilan sampel dengan suatu pertimbangan tertentu, maka sampel yang di ambil adalah 40 orang dari anggota BMT Baytul Ikhtiar Bogor, BMT ItQan Bandung, BMT Amanah Bersama Bandung dan BMT Ibadurrahman Sukabumi. Dalam mengumpulkan data, peneliti menggunakan kuesioner, wawancara dan studi dokumentasi. Sedangkan teknik untuk menganalisa data yaitu menggunakan analisis Regresi Linier sederhana. Dalam penelitian ini, peneliti menggunakan 
bantuan program software SPSS 23.0 for windows. Untuk mengetahui pengaruh variabel bebas dan variabel terikat digunakan rumus analisis regresi sederhana yaitu:

$\mathrm{Y}=\mathrm{a}+\mathrm{bX}$

dimana:

$\mathrm{X}=$ Variabel Independen (Pembiayaan Mikro Syariah)
$\mathrm{Y}=$ Variabel Dependen (Tingkat

Perkembangan Usaha UMKM)

$\mathrm{a}=$ Konstanta

$\mathrm{b}=$ Koefisien regresi

\section{HASIL DAN PEMBAHASAN}

1. Uji asumsi klasik

a. Uji Normalitas

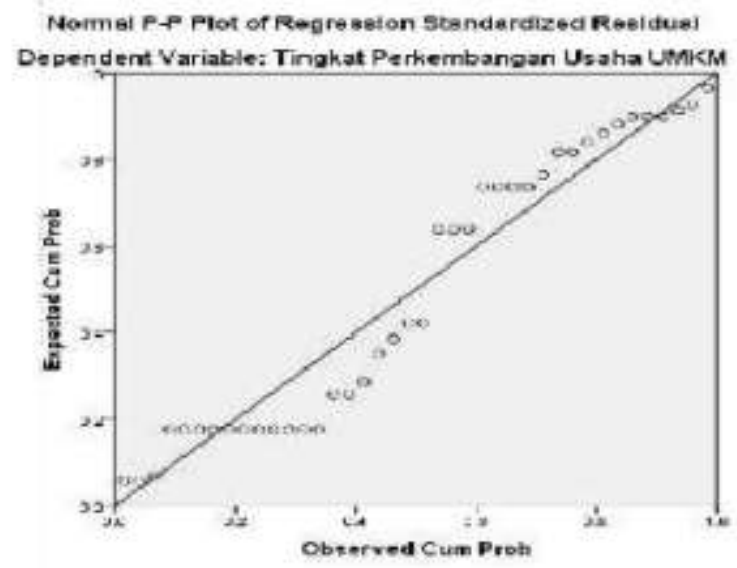

Gambar 1

Uji Normalitas

Adapun tujuan dari Uji Normalitas yaitu untuk menguji apakah hasil dalam pengolahan regresi, variabel dependen (Tingkat Perkembangan Usaha UMKM) dan independen (Pembiayaan Mikro Syariah) yang mana setiap variabelvariabelnya mempunyai distribusi normal atau tidak, mendekati normal dapat

b. Uji Heterokedastisitas dilakukan dengan uji PP plot standardized residual. Berdasarkan gambar di atas terlihat penyebaran disekitar jalur garis diagonal. Oleh karena itu berdasarkan uji normalitas dapat dinyatakan bahwa data terdistribusi normal.

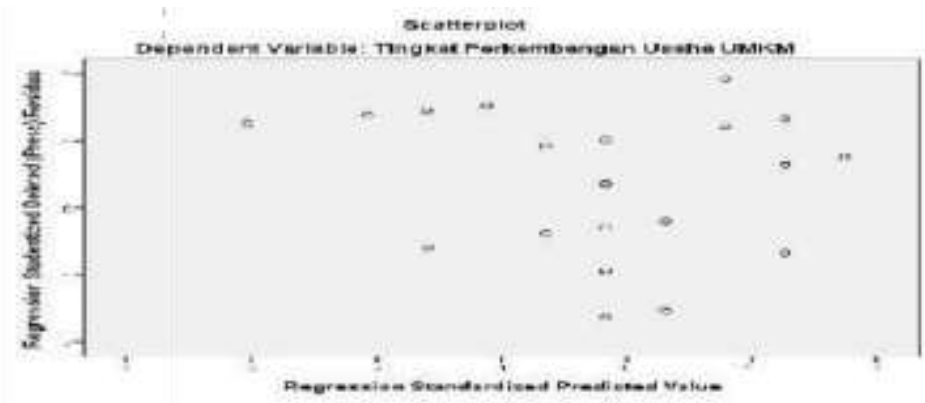

Gambar 2 Uji Heterokedastisitas 
Gambar 2 menunjukkan adanya penyebaran titik-titik secara acak yang tidak berkumpul atau tidak membentuk pola yang jelas/teratur, tersebar baik terlihat di atas dan di bawah angka 0 terhadap sumbu $\mathrm{Y}$, sehingga hasil menunjukkan tidak terjadinya heterokedastisitas pada model regresi ini.

\section{Uji Hipotesis}

Tabel 2

Uji F

ANOVA $^{\mathrm{a}}$

\begin{tabular}{|c|c|c|c|c|c|c|}
\hline Model & & $\begin{array}{l}\text { Sum of } \\
\text { Squares }\end{array}$ & Df & Mean Square & $\mathrm{F}$ & Sig. \\
\hline \multirow[t]{3}{*}{1} & Regression & 1557.600 & & 389.400 & 61.875 & $.000^{\mathrm{b}}$ \\
\hline & Residual & 2076.798 & 38 & 35.807 & & \\
\hline & Total & 3634.398 & 39 & & & \\
\hline
\end{tabular}

a. Dependent Variable: Tingkat Perkembangan Usaha UMKM

b. Predictors: (Constant), Pembiayaan Mikro Syariah

Terlihat dari pengolahan data di atas bahwa nilai $F_{\text {hitung }}>F_{\text {tabel, }}$ yaitu 61.875 $>3.24$. Hal ini dengan tingkat signifikan $0.000<0.05$, berarti $\mathrm{H}_{0}$ ditolak sedangkan
$\mathrm{H}_{\mathrm{a}}$ diterima. Berarti Pembiayaan Mikro Syariah berpengaruh signifikan terhadap Tingkat Perkembangan Usaha UMKM.

\section{Uji Regresi Sederhana}

Tabel 3

Uji t

\begin{tabular}{|c|c|c|c|c|c|c|}
\hline \multirow[t]{2}{*}{ Model } & \multicolumn{2}{|c|}{$\begin{array}{c}\text { Unstandardized } \\
\text { Coefficients }\end{array}$} & \multirow{2}{*}{$\begin{array}{c}\begin{array}{c}\text { Standardized } \\
\text { Coefficients }\end{array} \\
\text { Beta }\end{array}$} & \multirow[t]{2}{*}{ thitung } & \multirow[t]{2}{*}{ Sig. } & \multirow{2}{*}{$\begin{array}{l}\text { Keputusan } \\
\text { terhadap } \mathrm{H}_{0}\end{array}$} \\
\hline & B & Std. Error & & & & \\
\hline Constant & 1.496 & 2.970 & & .408 & .835 & \\
\hline X1 & .852 & .085 & .691 & 9.877 & .000 & Diterima \\
\hline
\end{tabular}

Tabel di atas terlihat bahwasanya nilai constanta sebesar 1.496, sedangkan nilai pembiayaan mikro syariah adalah 0.852. Sehingga persamaan regresinya yaitu: $\mathrm{Y}=1.496+0.852 \mathrm{X}$. Konstanta sebesar 1.496 menyatakan bahwa jika tidak ada Pembiayaan Mikro Syariah, maka nilai dari Tingkat Perkembangan Usaha UMKM sebesar 1.496.
Koefisien regresi $\mathrm{X}$ sebesar 0.852 menyatakan bahwa setiap penambahan 1 nilai Pembiayaan Mikro Syariah, maka nilai Tingkat Perkembangan Usaha UMKM bertambah sebesar 0.852. Dari tabel di atas juga terlihat $t_{\text {hitung }}>\mathrm{t}_{\text {tabel, }}$ yaitu $9.877>3.24$. Dari perhitungan tersebut maka $\mathrm{H}_{0}$ ditolak dan Ha diterima, terlihat ada pengaruh 
Uus Ahmad Husaseni, Tini Kusmayati Dewi, Pengaruh Pembiayaan Mikro Syariah

Terhadap Tingkat Perkembangan Usaha Mikro Kecil Menengah (UMKM)

Pada Anggota BMT dI Jawa Barat

Pembiayaan Mikro Syariah terhadap Tingkat Perkembangan Usaha UMKM

4. Uji Determinasi (R-Square

Tabel 4

Uji determinasi (R-Square)

Model Summary

\begin{tabular}{|l|c|r|r|r|}
\hline Model & R & R Square & $\begin{array}{c}\text { Adjusted R } \\
\text { Square }\end{array}$ & $\begin{array}{c}\text { Std. Error of } \\
\text { the Estimate }\end{array}$ \\
\hline 1 & $.755^{\mathrm{a}}$ & .529 & .489 & 5.98388 \\
\hline
\end{tabular}

a. Predictors: (Constant), Pembiayaan Mikro Syariah

b. Dependent Variable: Tingkat Perkembangan Usaha UMKM

Dari uji determinasi di atas menunjukkan bahwa nilai R-Square sebesar 0.529 atau $52.90 \%$, hal ini menunjukkan variabel Tingkat Perkembangan Usaha UMKM (Y) dipengaruhi oleh variabel Pembiayaan Mikro Syariah (X). Sisanya sebesar $47.10 \%$ adanya kontribusi variabel lain yang tidak termasuk di dalam penelitian ini.

\section{KESIMPULAN}

Pembiayaan Mikro $\begin{array}{r}\text { Syariah } \\ \text { terhadap }\end{array}$
berpengaruh signifikan
perkembangan UMKM pada anggota BMT
Baytul Ikhtiar Bogor, BMT ItQan Bandung,
BMT Amanah Bersama Bandung dan BMT
Ibadurrahman Sukabumi Hal ini
dinyatakan dari hasil uji t adanya pengaruh
Pembiayaan Mikro Syariah terhadap
Tingkat Perkembangan Usaha UMKM pada
anggota BMT dengan nilai thitung $>t_{\text {tabel atau }}$ atingina
$9.877>3.24$ di mana nilaisignifikansinya
$0.000<0.05$. Pembiayaan Mikro Syariah
diperoleh angka koefisien determinasi R-
Square = sebesar 0.529 atau 52.90\%. Hal
ini terlihat bahwa variabel independen
Pembiayaan Mikro Syariah dalam
menjelaskan variabel dependen Tingkat
Perkembangan Usaha UMKM pada anggota
BMT sebesar 52.90\%, sisanya sebesar

$47.10 \%$ dijelaskan oleh variabel lain di luar model yang tidak diteliti. Berdasarkan hasil pengujian uji $\mathrm{F}$, nilai $\mathrm{F}_{\text {hitung }}>\mathrm{F}_{\text {tabel }}$ adalah $61.875>3.24$ dengan hipotesis $\mathrm{H}_{0}$ ditolak dan $\mathrm{H}_{\mathrm{a}}$ diterima dengan signifikansi $0.000<$ 0.05 maka dapat disimpulkan yaitu variabel Pembiayaan Mikro Syariah berpengaruh signifikan terhadap Tingkat Perkembangan Usaha UMKM pada anggota BMT Baytul Ikhtiar Bogor, BMT ItQan Bandung, BMT Amanah Bersama Bandung dan BMT Ibadurrahman Sukabumi.

\section{DAFTAR PUSTAKA}

Afkar, Taudlikhul. 2017. "Pengaruh Pembiayaan Usaha Mikro, Kecil, Menengah (UMKM) dan Kecukupan Modal Terhadap Kemampuan Mendapatkan Laba Dari Aset Perbankan Syariah Di Indonesia". Al-Uqud: Journal of Islamic Economics, Vol. 1, No. 2, pp. 131-147.

Agyapong, Daniel. 2010. "Micro, Small and Medium Enterprises' Activities, Income Level and Poverty Reduction in Ghana-A Synthesis of Related Literature". Journal of 
Business and Management, Vol. 5, No. 12, pp. 20-31.

Alma, Buchari. 2010. Kewirausahaan. Bandung: Alfabeta.

Amalia, Euis. 2009. Keadilan Distributif dalam Ekonomi Islam: Penguatan Peran LKM dan UKM di Indonesia. Jakarta: Raja Grafindo Persada.

Anggraeni, Feni Dwi., Hardjanto, Imam., Hayat, $\quad 2012$. "Pengembangan Usaha Mikro, Kecil, Dan Menengah (UMKM) Melalui Fasilitasi Pihak Eksternal Dan Potensi Internal (Studi Kasus pada Kelompok Usaha "Emping Jagung" di Kelurahan Pandanwangi Kecamatan Blimbing, Kota Malang)". Jurnal Administrasi Publik (JAP), Vol. 6, No. 6, pp. 1286-1295.

Antonio, Muhammad Syafi'i. 2001. Bank Syariah, dari Teori Ke Praktek. Jakarta: Gema

Insani Press.

Bank Indonesia. 2010. Laporan Perkembangan Perbankan Syariah tahun 2009. Jakarta: Direktorat Perbankan Syariah, Bank Indonesia.

Bastian, Bustami. 2007. Mari Membangun Usaha Mandiri. Cet. Yogyakarta: Graha Ilmu.

Darawati, Ni Made Dwi dan Wenagama, I Wayan. 2013. "Efektivitas dan Dampak Program Dana Penguatan Modal Lembaga Usaha Ekonomi Pedesaan (DPM-LUEP) Terhadap
Pendapatan dan Kesempatan Kerja Petani Padi di Kabupaten Tabanan". Jurnal Ekonomi Pembangunan. Vol. 2, No. 1, pp. 449-456.

Kara, Muslimin dan Jamaluddin. 2010. Pengantar Kewirausahaan. Makassar: Alauddin Press.

Karim, A. 2009. Fiqh Muamalat dan Perbankan Syariah. Seminar Syariah Islam. Jakarta: Muamalat Institute.

Nizarul, Alim. 2009. Pembiayaan Syariah Untuk Usaha Mikro dan Kecil: Studi KasusDan Solusi. Surabaya: PT. Bina Ilmu.

Peraturan Menteri Keuangan No. 135/PMK.05/2008 tentang Fasilitas Penjaminan Kredit Usaha Rakyat yang telah diubah dengan Peraturan Menteri Keuangan No. 10/PMK.05/2009.

Pramayati, Alika. 2008. Studi Kelayakan Bisnis Untuk UKM. Yogyakarta: Media Prindo.

Prawirokusumo, Soeharto. 2000.

Kewirausahaan dan Manajemen Usaha Kecil. Yogyakarta: BPFE Yogyakarta.

Purnomo, Ratno dan Sri Lestari. 2010." Pengaruh Kepribadian, SelfEfficiacy dan Locus of Control Terhadap Persepsi Kinerja Usaha Skala Kecil dan Menengah". Jurnal Ekonomi Pembangunan. Vol. 1, No. 2, pp. 201-212.

Tambunan, D. T. 2009. UMKM di Indonesia. Bogor: Ghalia Indonesia. 